\title{
O desenvolvimento biológico em conexão com a guerra ${ }^{1}$
}

\author{
MARIA ENEIDA DE ALMEIDA
}

\section{RESUMO}

O século XX foi cenário da construção de um sistema para a operacionalização da ciência estratégica das grandes potências, chamada Big Science. Este sistema é constituído por uma vasta rede institucional integrada, o "complexo militar-industrial-acadêmico", que desenvolve pesquisas estratégicas e direciona a ciência de ponta. O objetivo deste estudo foi investigar a lógica desta construção sob a ótica do poder, fazendo um contraponto entre os desenvolvimentos tecnológicos da Física e da Biologia. Os movimentos de poder identificam algumas características que, em tese, refletem o incentivo para indução do desenvolvimento científico da modernidade, potencializado na era atômica com a fabricação de armas de destruição em massa, as armas de alta tecnologia. Nesta perspectiva, buscamos a relevância do desenvolvimento biológico de interesse político-militar, tomando por base a fabricação de três gerações de armas ao longo do século XX, com crescente posicionamento na corrida armamentista. Esta análise envolve as décadas de 1940 até 1980, na busca de demonstrar uma convergência técnico-política nas trajetórias do desenvolvimento biológico e da guerra biológica, que culminou numa conexão científico-militar no início da era biotecnológica.

Palavras-chave: biotecnologia; Big Science; poder; guerra biológica; história.

Recebido em: 31/01/2007.

Aprovado em: 17/06/2007. 


\section{Introdução}

A centralidade da Biologia vem chamando a atenção dos físicos. Uma pesquisa do relatório do Conselho Nacional de Pesquisa dos Estados Unidos, de 2002, elaborado para assessorar o governo federal na formulação de sua política científica, ressaltou o prestígio crescente da Biologia em detrimento da Física, e demonstrou que os orçamentos americanos destinados a pesquisas científicas mudaram suas prioridades.

Nos últimos vinte anos, o prestígio da velha soberana foi abalado seriamente pelo crescimento da Biologia, ou mais precisamente, da genética. De 1987 para cá, a massa de doutores em genética cresceu quatro vezes e meia, enquanto a da Física apenas triplicou. Parece que não há mais ciência, só genômica (Folha de São Paulo, 2002).

Isto pode ser considerado um estímulo para a geração de novos conhecimentos, os quais partem de projetos que possibilitam os meios adequados para o avanço da ciência, porém sob uma outra ordenação, que não mais com a exclusividade da Física.

Para bem introduzir este texto, é preciso reconhecer a profundidade e a velocidade das transformações que se deram no campo da Biologia, sobretudo nas três últimas décadas do século XX, levando esta ciência para a centralidade da Big Science. Big Science é uma expressão que se encontra na dimensão político-militar da ciência, tem o objetivo de elaborar e executar projetos de pesquisa dirigidos à preparação para a guerra, e à manutenção da liderança científica mundial. Desde a II Guerra Mundial, a Big Science vem refletindo as diretrizes da doutrina do Estado americano, atendendo à demanda do poder, com o objetivo de manutenção da sua posição no sistema mundial. Nesta perspectiva, reconhecemos a Big Science como um mecanismo fundamental da doutrina estratégica das grandes potências, independentemente do campo de sua ciência central, sendo o caso da Física na era atômica bastante semelhante ao caso da Biologia, mais recentemente.

Não é difícil identificar os momentos que precederam as transformações no campo da Biologia, pois seu desenvolvimento deslocou as fronteiras científicas, abriu novos campos de pesquisas e, consequientemente, possibilitou uma gama de invenções e inovações, de tecnologia cada vez mais avançada. Para nossa pesquisa, identificamos como importantes marcos para o avanço tecnológico da Biologia: a descoberta do DNA em 1944 - o "fio condutor" entre todas as 
espécies; a descoberta de sua estrutura em dupla hélice em 1953; e a invenção da biotécnica DNA recombinante em 1970, que produziu alta densidade técnica e possibilitou a decodificação do genoma humano.

A invenção do DNA recombinante - na atualidade uma biotécnica de rotina nos laboratórios de biotecnologia - deu o impulso original para a disrupção da revolução biotecnológica, ao dar condições para cortar, costurar e duplicar fragmentos genéticos, recombinando o DNA de qualquer ser vivo, independentemente do reino ou da espécie, como uma "máquina de costura biológica" (RIFKIN, 1999). Essa técnica é mais conhecida por manipulação genética, e se enquadra na área de bioengenharia. O efeito desta invenção, com crescente velocidade das inovações decorrentes, alterou todas as bases conceituais e estrutura tradicional das pesquisas biomédicas, causou uma ruptura científica e abriu uma "nova dimensão" para a vida e para os seres vivos. Esta transformação científica foi uma mudança de paradigma no campo da Biologia.

Todo tipo de manipulação genética, que antes se enquadrava no campo da utopia da pesquisa científica, passou a se materializar e abrir infinitas possibilidades de pesquisas. Consideramos a biotécnica DNA recombinante o passo seminal da ciência genômica, a qual se tornou a ciência de ponta oficialmente reconhecida no ano 2000 e considerada a grande ciência do século XXI. Esta biotécnica foi o marco fundador da possibilidade de transformação genômica dos seres vivos e de criação de novas espécies, sendo o princípio ativo para as pesquisas biotecnológicas que se sucederam.

Dentro do contexto dos grandes avanços da Biologia, uma questão fundamental para este estudo é a forma através da qual as transformações, decorrentes da alta tecnologia, podem corresponder à sobreposição da Física cujo primeiro projeto da Big Science foi o Projeto Manhattan da bomba atômica, iniciado em 1941 -, em termos de prioridades em pesquisas estratégicas para o Estado (figura 1). Para o campo da Biologia, o desenvolvimento biotecnológico já era campo estratégico da defesa nacional nas grandes potências, mesmo antes do crescente sucesso do Projeto Genoma Humano elaborado a partir de 1985, desenvolvido na década de 1990, com sua apoteose no ano 2000. A consolidação do papel da genômica, na ponta da ciência, foi-se dando frente aos avanços decorrentes da ciência de primeira linha.

Para apontar um caminho básico de entendimento desta questão, é importante destacar que uma das características fundamentais da ciência de ponta é seu uso dual, cujo significado é a imanência de seu duplo papel: atende 
tanto interesses civis - para melhoria da qualidade de vida das populações, quanto interesses militares bélicos - que não costumam poupar vidas na busca das conquistas científicas. Neste estudo focamos exclusivamente o uso militar.

Crescentes foram os interesses militares que apoiaram o desenvolvimento das novas biotécnicas como a do DNA recombinante a partir da década de 1970. Foi a partir deste ponto do processo científico que o armamento biológico alcançou a alta tecnologia, potencializando o interesse militar de seus produtos. Devido à intensidade das pesquisas desenvolvidas pelos países da vanguarda biotecnológica, sobretudo nos Estados Unidos, os temores sobre o rumo da ciência cresceram e os laboratórios de DNA recombinante passaram a atrair atenção pela possibilidade de produzirem uma nova geração de agentes infecciosos devastadores para uso bélico (WILKIE, 1994). Entretanto, o potencial da biotecnologia sempre foi uma questão controversa na comunidade biomédica. Apesar de fatores contraditórios da nova ciência, seu desenvolvimento foi acelerado. Como este fato pode ser explicado?

Para compreender a transformação do domínio da energia nuclear ao domínio da genômica, fizemos um contraponto da Biologia em relação à Física. A era atômica teve como ciência central, a Física, possibilitando a construção da bomba, e abriu a corrida nuclear, com o desenvolvimento de uma gama de novas armas (figura 2). Para Carlos Medeiros, cuja hipótese de pesquisa relacionamos neste estudo, após a II Guerra Mundial a velocidade do desenvolvimento tecnológico teve influência da competição pelas armas (MEDEIROS, 2004). Partindo desta linha de análise desenvolvemos nosso argumento pois, em tese, as transformações no campo da Biologia podem estar estreitamente associadas à corrida armamentista e, da mesma forma, terem sido impulsionadas por uma competição pelas armas.

Nossa hipótese se justifica quando verificamos que o desenvolvimento biológico teve papel fundamental nas estratégias de segurança das grandes potências, como componente-chave da lógica armamentista, desde o início do século XX. Do ponto de vista político-militar, ciência estratégica é aquela que concentra o poder do Estado na produção de armas cada vez mais sofisticadas para a competição armamentista. Em busca da forma pela qual a genômica conquistou seu lugar de destaque, outrora ocupado pela Física, abordaremos a questão sobre a maneira - ou uma das maneiras - pela qual os Estados Unidos impulsionaram seu desenvolvimento biotecnológico, dentro da perspectiva de 
que, tradicionalmente, as pesquisas estratégicas americanas são controladas pelo Pentágono, sustentadas pela Fundação Nacional de Ciência dos Estados Unidos (CORNWELL, 2003), e têm papel fundamental na manutenção do poder mundial.

\section{Desenvolvimento tecnológico}

As guerras são decisivas para o desenvolvimento da tecnologia de ponta. Segundo Jared Diamond (2003), na trajetória das civilizações e das sociedades, a tecnologia desenvolvida em momentos diferentes e em ritmos descompassados nos cinco grandes continentes moldou o mundo em sua diversidade. As guerras e as ameaças de guerra foram fundamentais nas fusões das sociedades e no desenvolvimento tecnológico de cada uma. A inovação e a difusão tecnológica, junto com uma organização política centralizada, foram decisivas para a questão da conquista. Isto se confirma com William McNeill (1982), quando analisou as transformações que ocorreram na busca pelo poder a partir da descoberta da pólvora na China, aproximadamente no ano 1000. Com Geoffrey Parker (1996) entendemos que as armas de fogo chegaram ao Ocidente por volta do século XV, quando se iniciou um processo ocidental de fabricação e aperfeiçoamento tecnológico da guerra. Após 1500, as conquistas de além-mar impulsionaram essas transformações, causando uma ruptura no paradigma bélico-militar ocidental existente até então, e surgiu uma nova forma de fazer guerra, com organização militar especializada, armas mais potentes e instrumentos de guerra cada vez mais sofisticados.

Uma das características do início da era moderna foi o nascimento do Sistema Mundial Moderno (WALLERSTEIN, 1974), que organizou o mundo em Estados, cujas relações interestatais conflituosas, e ao mesmo tempo complementares, foram definindo seus territórios, suas finanças e suas ciências. No século XVII, dentro do movimento da Revolução Científica, a ciência moderna nasceu nos primeiros Estados modernos, originalmente circunscritos nos territórios da Inglaterra, Holanda e França. Desde o princípio, a ciência tem sido um dos suportes fundamentais na busca pelo poder por meio da guerra, sendo possível identificar o desenvolvimento científico como uma estratégia da modernidade para acumular mais poder. Os desdobramentos da ciência, suas invenções e inovações sempre foram de grande interesse militar para o planejamento da conquista, e a ciência estratégica passou a refletir o poder militar dos Estados. Segundo Hans Morgenthau (2003), o destino de nações e 
civilizações foi freqüientemente determinado pelo diferencial tecnológico de sua capacidade militar, sendo a corrida armamentista uma "política de competição" entre as nações, e os armamentos, os "instrumentos" desta política. Nesta visão, é o poderio militar equivalente que mantém, ou restabelece, no Sistema Mundial Moderno, o equilíbrio do poder entre as grandes potências. Este equilíbrio, de caráter dinâmico e instável, tem, em última instância, a finalidade de obter a liderança na corrida armamentista.

Paul Kennedy (1989) diz que, na modernidade, se observa uma dinâmica de poder no sistema mundial, impulsionada pelos aspectos econômicos e inovações tecnológicas, de impacto sobre estruturas sociais, sistema político, poder militar e posição dos Estados e impérios. A íntima interação econômica e tecnológica das nações nas guerras entre as grandes potências é o mecanismo essencial com que cada Estado se empenha, igualmente, para conquistar a vitória. Por sua vez, a razão principal da queda dos impérios ao longo da história é o declínio do desenvolvimento tecnológico, pelo fato de o Estado não ter logrado a manutenção do seu nível tecnológico pari passu com o Estado que o liderava no mundo, no momento de sua queda. Isto é, tecnologicamente, um Estado passa a desenvolver tecnologia de ponta mais avançada, o que significa a ultrapassagem técnica, passando a ter as armas mais radicais, posicionando a liderança tecnológica no mundo, ao sobrepujar o poder do Estado, ou império, em declínio.

A estratégia militar com alta tecnologia se evidencia no empenho de todo Estado que tem a pretensão de aumentar seu poderio militar, com finalidade de se tornar, ou se manter, ao mesmo tempo rico e forte. Um Estado rico e forte, ou uma grande potência, é, dentro da linguagem através da qual se articulam as relações interestatais, aquele que tem condições de fazer a guerra, deflagrála, ser vitorioso, proclamar a paz e, dentro desta paz, preparar-se para a guerra seguinte, velada ou declarada. Porque, desde o nascimento deste sistema, existe uma constante que é a potencialização contínua da corrida armamentista.

Aprofundando esta questão, para José Luís Fiori, existe "uma lógica implacável" na competição entre as grandes potências, que "obriga" todos os Estados-membros a participar da corrida armamentista, se "armando" permanentemente com "tecnologia de ponta", expandindo seu poder, com a finalidade de preservar a segurança, a paz e a tranqüilidade de suas populações. Sendo, portanto, a guerra, uma "possibilidade constante" dentro do jogo interestatal, e um "componente essencial" do cálculo estratégico do poder. Neste sentido, é fundamental "ser" a vanguarda tecnológica para assegurar o lugar 
de domínio no sistema mundial, pois "a presença contínua da "guerra virtual" atua como estímulo para a mobilização interna e permanente de recursos para a guerra (FIORI, 2004, p. 27).

Ao longo do século XX, os Estados Unidos exerceram seu poder de maneira expansiva, sobretudo com o domínio da ciência no avanço da era atômica, sob o mundo bipolarizado. Esta era desencadeou uma nova transformação da guerra, com prioridade científico-militar. As armas de destruição em massa passaram a ser a estratégia dominante no jogo de poder mundial. Com Raymond Aron (2002) aprendemos que, a partir de 1945, tanto as novas armas quanto o caráter da "guerra hipotética" tornaram-se marcos diferenciais para a diplomacia, interesses, idéias, práticas e desempenho de novos atores no sistema político mundial, na abertura da era atômica, rompendo o paradigma da guerra, vigente até então.

Mais especificamente, conforme hipótese de Carlos Medeiros (2004), a trajetória tecnológica dos Estados Unidos, após a II Guerra Mundial, foi desenvolvida como um empreendimento militar para ganhar a Guerra Fria, com construção de armas de alta tecnologia. Desta forma, o conhecimento científico de ponta, com seus desdobramentos em novos projetos de pesquisa de ordem político-militar, com associações institucionais de cientistas de vanguarda, foram componentes essenciais para o acirramento bipolar ascendente da era atômica.

A partir deste ponto, as armas de destruição em massa passaram a ser o principal incentivo da corrida armamentista. Para atender a esta demanda militar foi constituída a Big Science, com finalidade de desenvolvimento da ciência estratégica.

\section{O caso da Física e a Big Science}

O complexo "militar-industrial-acadêmico" americano foi construído para dar suporte ao Projeto Manhattan, o primeiro grande projeto da era atômica que, com rapidez, construiu cidades para sua operacionalização, inicialmente constituído por 150 mil trabalhadores, contratados em segredo absoluto. As raízes deste complexo estão nas últimas décadas do século XIX, quando se iniciou a estruturação da indústria pesada para fortalecimento dos encouraçados. Na primeira década do século XX, os orçamentos das Forças Armadas para a indústria bélica aumentaram, e começou uma articulação entre os setores militar e industrial, visando à aprovação no Congresso, para liberação de recursos 
financeiros crescentes do Pentágono. A partir da década de 1920, foram desenvolvidos "planos de mobilização e de cooperação industrial-militar, nos Estados Unidos" (MONIZ-BANDEIRA, 2005, p. 212). Esta estrutura, própria para fabricação de arsenais bélicos com produção industrial, sustentou uma dinâmica importante do sistema produtivo americano. Com a extensão do militarismo político, o Estado intensificou a preparação e o planejamento militar, frente ao contexto intensivamente bélico da primeira metade do século XX.

$\mathrm{O}$ aumento na densidade político-militar, com a detonação das duas bombas atômicas pelos Estados Unidos, fez com que as outras grandes potências buscassem equiparação tecnológica, implantando seus programas nucleares, e anunciando ao mundo sua participação na corrida armamentista. O propósito da Pax Americana, de paz estável entre as grandes potências, se baseou no equilíbrio do crescente poderio militar, o qual poderia conferir a uma só pessoa a decisão de destruir a vida de centenas de milhares de outras. Este equilíbrio mundial de forças, balizado pela bipolaridade ao longo da Guerra Fria, foi um equilíbrio de terror, especificamente de "terror nuclear" (MORGENTHAU, 2003). Ou ainda, um equilíbrio do poder nuclear, onde a ameaça e a contraameaça têm o mérito de preservar a paz.

Os avanços da Física, desenvolvidos por um grupo internacional de grandes físicos tendo Einstein como expoente, foram incorporados a um processo de concentração e polarização de pesquisas científico-tecnológicas, de caráter político-militar. Foi quando a Física passou a ser uma ciência estratégica, devido ao aumento da competitividade da corrida nuclear e, nesta perspectiva, foi a ciência central da Big Science. As instituições acadêmicas e de pesquisas passaram a ser o centro vital para a materialização das estratégias militares, integrando e articulando o sistema tecnológico de inovação para as causas de defesa nacional, com detenção do segredo estratégico, para a operacionalização da grande ciência. O "complexo militar-industrial-acadêmico" foi arquitetado pelo criador do sistema de inovação americano e diretor do Conselho de Pesquisas para a Defesa dos Estados Unidos a partir de 1941, Vannevar Bush, que havia encomendado mais de dois mil programas de pesquisas estratégicas e contratado milhares de cientistas e técnicos, para desenvolvimento de projetos militares, em empresas como Du Pont, General Electric e em laboratórios das grandes universidades como o Instituto de Tecnologia de Massachusetts (MIT) ${ }^{2}$ e Instituto de Tecnologia da Califórnia (CORNWELL, 2003) ${ }^{3}$. Criou também o Departamento de Pesquisas Estratégicas, origem ao Conselho de Pesquisas 
para a Defesa Nacional ${ }^{4}$ e ao seu sucessor, o Gabinete de Pesquisas para a Defesa $^{5}$, órgãos que desenvolveram a bomba atômica.

A partir do sucesso do Projeto Manhattan, com a detonação de seu produto sobre Hiroshima e Nagasaki em 1945, novos projetos do planejamento estratégico militar americano conectaram as universidades ao Departamento de Defesa (DoD) ${ }^{6}$ e ao Pentágono. Foram criados os grandes departamentos de pesquisas militares como o Departamento de Projetos de Pesquisas Avançadas $^{7}$, a Agência de Projetos de Pesquisa Avançada ${ }^{8}$ e o Conselho de Pesquisas para a Defesa ${ }^{9}$, com finalidade exclusiva de promover descobertas científicas e invenções de ponta para armamentos radicalmente novos. Aidéiachave que permeava a dinâmica de desenvolvimento destes projetos era que todas as instituições e indústrias trabalhassem em parceria com o Estado, em alinhamento às diretrizes da doutrina americana. Por meio desses interesses e de grandes fomentos do Estado, a Big Science foi impulsionada.

As universidades, como pilares de sustentação da pesquisa científica, consolidavam os elos do mecanismo da Big Science para a construção de armas de alta tecnologia. O MIT e o Laboratório Eletrônico de Stanford ${ }^{10}$ foram instituições acadêmicas originárias desta conexão, anexando-se depois, as universidades de Harvard, Columbia e da Califórnia. O desafio era alcançar alta tecnologia militar e construir a "arma superior" (MEDEIROS, 2004). O conceito de armamento tecnologicamente superior significa um sistema, cuja dinâmica faz a interação entre cinco fatores: doutrina estratégico-militar, pesquisa e seleção de idéias (Ciência e Tecnologia), inovação e invenção (Pesquisa e Desenvolvimento), táticas para combate e novas estratégias militares. Esses fatores guiam a ciência de ponta na missão a ser desempenhada pelo armamento. Nesta concepção, são priorizadas as inovações e invenções provenientes de idéias estratégicas para construção de armas radicais. Nesta lógica, a competição nuclear decidiria a liderança tecnológica no mundo.

A hipótese de a inovação tecnológica americana ser um empreendimento militar desde a II Guerra Mundial, mais do que um movimento de inovação endógena do mercado, permite esclarecer que a corrida pela "arma superior" foi uma estratégia que possibilitou a funcionalidade do "complexo militarindustrial-acadêmico", com indução de organizações complexas em gerenciamento, informações e sofisticado conhecimento científico, além de novos meios de difusão de tecnologia no campo industrial. Para movimentar com maior velocidade este mecanismo, o desafio passou a ser a agilidade de um 
sistema que permitisse redução do tempo entre invenção e inovação, e a aplicação deste conhecimento no sistema produtivo americano. Os produtos apropriados de "uso dual" deram possibilidade para que a "velocidade do progresso técnico tenha sido, por seu turno, fortemente influenciada pela competição pelas armas" (MEDEIROS, 2004, p. 230). No caso da Física como ciência estratégica, a competição entre as grandes potências foi pautada na tecnologia atômica de última geração, o que indica que tenha acelerado o desenvolvimento científico em potencial crescente.

\section{O caso da Biologia e a Big Science}

No caso da Biologia, é importante salientar que sua busca essencial sempre foi o desvendamento da vida. No século XX, a ciência deu condições para o desenvolvimento de instrumentos que permitiram a análise dos elementos fundamentais dos seres vivos. Desde 1944, com a descoberta do DNA, e, sobretudo a partir de 1953, com a descoberta de sua estrutura, o processo biotecnológico começou a ter maior precisão e passou a existir uma conexão cada vez mais estreita com alta tecnologia da Física. Esta conexão impulsionou a abertura de novos campos científicos. A biologia molecular é um campo de fusão da Física e da Biologia, em nível molecular, e o nascimento desta ciência ao longo da década de 1940 reposicionou as fronteiras da ciência. O DNA passou a ser o princípio ativo para abertura de novas pesquisas biotecnológicas.

Surgiu a idéia de um projeto que fosse capaz de desvendar o genoma dos seres vivos. Iniciou-se, então, a elaboração de projetos para estudo dos genomas de animais e vegetais, e uma agenda biotécnica de longo prazo para o Projeto Genoma Humano ${ }^{11}$. Na década de 1950, já se discutia que a utilização desta nova tecnologia para uso militar era uma perigosa ameaça. Os cientistas da vanguarda enfrentavam desafios inerentes à dualidade da biotecnologia: para a vida e para a morte. Na década de 1960, a pesquisa pioneira de duplicação do DNA acentuou as expectativas militares do potencial biotecnológico (MILLER et al., 2002). Porém, foi na década de 1970, com a disrupção da Revolução Biotecnológica, que a produção de agentes patogênicos geneticamente modificados transformaria o paradigma da guerra biológica, porque esta transformação deu início a uma nova geração de armas biológicas, com virulência e letalidade sem limites. Desta forma, as armas biológicas deram à Revolução Biotecnológica um novo e radical significado, o qual justificou a conseqüente e crescente - exploração das fronteiras da Biologia. 
Para bem situar esta mudança de paradigma, é importante destacar que o desenvolvimento biológico em conexão com a guerra remonta à Antiguidade, muito antes de a Biologia existir enquanto ciência, o que se iniciou a partir da Revolução Científica do século XVII. A história da guerra mostra que ataques deliberados de agentes patogênicos foram utilizados como táticas de conquista, pois conhecimentos sobre doenças infecciosas sempre foram utilizados para fins bélicos, sendo que vários povos com vocação imperial se utilizaram dessa tática. Corpos infectados, carcaças de animais doentes, secreções putrefatas, fezes diarréicas, águas/alimentos contaminados e outros meios foram usados em invasões, com o objetivo de dizimar populações.

$\mathrm{Na}$ era moderna, este foi um caminho seguido pela Espanha para exterminar a civilização inca e a asteca; pela Inglaterra ao atacar os índios americanos no século XVIII; pelos Estados Unidos durante a guerra civil de meados do século XIX. No século XX, a ciência da Biologia passou a ser cada vez mais estratégica para a guerra, com a construção "científica" de armas biológicas. Foi reconhecido o uso deste tipo de armas pela Alemanha, na I Guerra Mundial e pelo Japão, na II Guerra Mundial. O armamento biológico sempre foi considerado um tipo de arma inferior, pelo baixo grau de tecnologia, o que confere reduzido custo para sua produção. Neste sentido, seu uso seria esperado somente por povos sem capacidade orçamentária, nem equipe científica, para usar a tecnologia mais avançada. Mas, apesar de a guerra biológica ser tradicionalmente considerada inferior, e mesmo uma forma desprezível de ameaçar - e, sobretudo de guerrear -, ela sempre foi uma alternativa dos povos que ambicionavam conquistar e colonizar novas regiões.

A conexão entre a ciência e a guerra biológica se confirma com a construção sistemática de armas biológicas pelas grandes potências. Na primeira geração de armas biológicas (DAVIDSON, 2005) houve a fabricação rudimentar de instrumentos, seleção de poucos agentes infecciosos e baixa produção de munição. Sua aplicação foi precária, sendo usada exclusivamente em sabotagens. Neste momento começou a experimentação biológica bélica. Entretanto os programas biológicos não eram organizados, nem tinham instalações específicas para desenvolvimento de agentes infecciosos. A microbiologia havia nascido como ciência no final do século precedente, e ainda não existiam empreendimentos para assimilação bélica. Mesmo assim, foi um programa desenvolvido pela Inglaterra, Estados Unidos, Alemanha, França e Rússia, dando início à corrida da Biologia. A partir da década de 1920, os primeiros programas 
ofensivos foram institucionalizados no Departamento de Guerra dos Estados, e iniciou-se uma articulação com institutos de pesquisas científicas e universidades, no Japão (1920), na França (1922), na União Soviética (1925) e na Alemanha (1940).

A segunda geração de armas biológicas (DAVIDSON, 2005) teve aperfeiçoamento técnico e científico, e foi desenvolvida pela Inglaterra (1934), Canadá (1940) e Estados Unidos (1943), além daqueles que estavam implementando a primeira geração. Com o propósito de sofisticar armamentos e estratégias bélicas, foram construídas instalações apropriadas para produção em larga escala, testes de campo, desenvolvimento e estudo de agentes infecciosos, construção de novos armamentos e instrumentos de disseminação. Houve implantação sistemática de programas biológicos em todas as grandes potências, e se acentuou a corrida da Biologia.

$\mathrm{Na}$ Guerra Fria, esta corrida foi polarizada entre Estados Unidos e União Soviética. Ambos implementaram seus programas, construíram complexos biológicos, aumentaram largamente a produção de agentes infecciosos e a fabricação de armas. Seus programas foram sendo aperfeiçoados na medida em que se davam os avanços biotecnológicos: de engenhos grosseiros, a equipamentos cada vez mais sofisticados. Na década de 1950, os americanos criaram petardos biológicos e os encheram de fréon para esfriá-los. Os soviéticos embalaram os petardos em esferas de plástico, a fim de absorver o calor da explosão e reduzir a pressão sobre os micróbios. O processo de avanço de técnicas para a guerra biológica teve seu ritmo próprio, pois se desenvolvia com grande limitação técnica (FRANZ et al., 1997). Esta limitação existiu até o momento da Revolução Biotecnológica.

As instituições que dinamizavam o complexo biológico e constituíam a Big Science vieram se organizando, de acordo com as demandas da doutrina estratégica frente à ameaça biológica permanente da Guerra Fria. Uma das funções do DoD era a produção de armas nucleares nos laboratórios de Los Alamos e de Lawrence Livermore. Um de seus departamentos, o Departamento de Energia (DoE), tinha a responsabilidade de formular projetos para produção de armas nucleares. Estes órgãos empreenderam o Projeto Manhattan a partir de 1941 e, após o lançamento das bombas, desenvolviam também pesquisas biotecnológicas sobre os efeitos da radiação nuclear nos genes humanos, com objetivo de desvendar o enigma das mutações genéticas (WILKIE, 1994). Uma divisão das ciências da vida havia sido mantida em Los Alamos desde o fim da 
II Guerra Mundial e, em 1983, em promissor momento da genômica, foi institucionalizado o banco de genes - Genbank, uma biblioteca genética, para aperfeiçoamento das técnicas e produção de inovações.

Os avanços da biotecnologia, da década de 1940 à de 1970, permitiram que, na década de 1980, a comunidade científica se decidisse pela elaboração do Projeto Genoma Humano, meta da vanguarda biotecnológica desde a década de 1950. O DoE tinha acesso a elevados recursos financeiros, além do interesse estratégico pelo avanço da genética humana e se dispôs a assumir a elaboração e a liderança do Projeto Genoma Humano (SFEZ, 1996). Novos empreendimentos do governo seriam capazes de seduzir o Congresso e a opinião pública para aprovar o financiamento de novas pesquisas estratégicas, como um projeto de desvendamento do genoma.

Esse empreendimento era considerado uma oportunidade ímpar, porque a idéia de uma sobreposição de projetos biológicos sobre as investigações dos efeitos nucleares teria mérito legitimamente ampliado, por se tratar da descoberta de doenças e melhoria da saúde pública. Desta feita, foram indicados dois laboratórios do governo americano, de reconhecida excelência na administração da Big Science, para executar o Projeto Genoma Humano: Los Alamos e Lawrence Livermore. A Guerra Fria se acirrava, potentes armas estavam sendo permanentemente construídas e a biotecnologia tinha potencial para ser o novo campo político estratégico. Eram prementes as ameaças biológicas soviéticas, e esse projeto tinha a perspectiva de solucionar o problema da proteção da população, bem como da proteção e reação dos soldados em campo de batalha.

Entretanto, a preocupação que permeava a comunidade biomédica era que todo esse esforço não deveria ser decidido exclusivamente pelos militares. Nesta perspectiva, considerada hostil, buscou-se evitar a possibilidade de pressão militar sobre os cientistas, cientes de que, nesta situação, os financiamentos do Congresso americano para pesquisas passariam somente pelo DoE. Desta forma, o campo da biomedicina se impôs através do Instituto Nacional de Saúde $(\mathrm{NIH})^{12}$. A inferência deste mega-organismo biomédico proporcionou, apesar de grandes controvérsias, um ajuste de poderes onde grande parcela do poder institucional americano estava em jogo. Era muito grande a envergadura do projeto a ser empreendido, além de que o campo da Biologia jamais havia lidado com recursos tão vultosos; ao mesmo tempo em que financiamentos estratosféricos eram tão comuns nos projetos do campo da Física. 
A solução encontrada foi pactuar uma parceria desses dois grandes órgãos do governo americano, o NIH e o DoE. O primeiro possuía o domínio do conhecimento biotécnico e científico, e o segundo tinha o domínio em administração e coordenação de grandes projetos militares. Em 1988, o Projeto Genoma Humano, de grande interesse estratégico político-militar, foi lançado nos Estados Unidos sob um consórcio científico internacional, com composição técnica de 17 países. Politicamente, o projeto teve condução americana, sem divisão de poder e sem difusão do conhecimento científico de ponta, sendo este o primeiro projeto da Big Science no campo da Biologia, mobilizando todo o sistema de inovação americana para construção de defesa e ataque relacionada à terceira geração de armas biológicas - as armas de alta tecnologia, constituídas por agentes infecciosos geneticamente modificados.

\section{Considerações finais}

Do ponto de vista desta pesquisa, é possível reconhecer a existência de uma estrutura e de uma dinâmica que impulsionam e dão operacionalidade à Big Science. A estrutura é o "complexo militar-industrial-acadêmico", um sistema institucional político-operacional integrado, capaz de responder à envergadura do projeto coordenado pelo Estado, com a missão de desenvolver a ciência para a construção de "armas superiores". A dinâmica se dá pelo fomento do Estado a este sistema, que impulsiona uma confluência de pesquisas estratégicas para invenções, inovações, novas estratégias e táticas bélicas. Desta maneira podemos dizer que a Big Science reflete a ciência central - da ponta tecnológica -, porque a centralidade de uma ciência estimula o fomento do Estado, direcionado a pesquisas estratégicas. No caso da corrida nuclear, a Física é a ciência central da Big Science; e no caso da corrida biológica, a Biologia é sua ciência central. Neste sentido, o domínio do "segredo" estratégico da ciência central da Big Science confere a liderança do Estado na corrida armamentista e reposiciona os outros Estados no jogo do poder mundial. Em última instância, o Estado que detém o segredo da ciência estratégica constrói, em primeiro plano, a "arma superior" de última geração.

Neste sentido, é possível apontar que uma das formas como os Estados Unidos vieram organizando seu sistema biotecnológico, desde a II Guerra Mundial, partiu da projeção da corrida nuclear sobre a corrida da Biologia, com interesses crescentes das possibilidades bélicas da genômica. Isto porque, em primeiro lugar, a Física e a Biologia se fundiram com o nascimento da biologia 
molecular, em um momento de grande desenvolvimento da Física atômica, levando para dentro do novo campo expectativas militares. Em segundo lugar, foram construídas cidades para o desenvolvimento do programa atômico tanto quanto para desenvolvimento do programa biológico; ambos com intensa articulação institucional, mobilizada sistematicamente para fins militares (HOBSBAWM ${ }^{1995)}$ ao longo da Guerra Fria, onde interagiam laboratórios das mais renomadas academias, cientistas da vanguarda tecnológica, grandes indústrias para produção de instrumentos, aparelhos e materiais bélicos em larga escala, e numerosos recursos humanos operacionais e especializados.

Ou seja, desde o princípio existiam complexos nucleares para a sustentação da era atômica, ao mesmo tempo em que existiam complexos biológicos - em diferentes graus de aplicabilidade, mas não por isso menos importantes, no que se refere ao grau de ameaça, a qual parece determinar, muitas vezes, a direção da pesquisa estratégica. E, em terceiro lugar, identificamos que a Biologia desempenhou papel fundamental dentro do sistema de pesquisas estratégicas americanas desde a II Guerra Mundial, principalmente a partir da década de 1980, com a decisão político-militar da doutrina americana de propulsão científica de combate à Guerra Fria, que por sua vez impulsionou o programa biológico ofensivo. Dentro desta perspectiva, a Revolução Biotecnológica foi um dos fatores principais para atender à defesa da nação e à preparação de proteção da população, com a construção de armas biológicas de terceira geração.

Do nosso ponto de vista, desta maneira a Biologia começou a sobrepujar a Física. Foi a partir da convergência de fatores tecnológicos, somados ao momento político-militar que, em tese, impulsionaram decisivamente a ascensão da genômica para a ponta da ciência, sobre a tradicional posição da Física.

$\mathrm{Na}$ atualidade, esse reposicionamento foi explicitado na Doutrina Bush de 2002, com os ataques de antrax em 2001, quando o desenvolvimento biotecnológico assumiu papel de grande destaque na defesa nacional. Segundo o Instituto de Medicina e o Conselho de Pesquisa Nacional da Academia Nacional dos Estados Unidos, em sua publicação Globalization, Biosecurity and the Future of the Life Sciences (USNA, 2001), o campo da biotecnologia está frente a um novo desafio para o século XXI: a "quarta geração" de armas biológicas. Nesta, a Nanobiotecnologia desempenha importante papel na velocidade das inovações tecnológicas, cuja fabricação de produtos de uso dual poderá aumentar a velocidade das inovações tecnológicas (figura 3). 
E, novamente, uma das formas de se evitar a difusão de conhecimento específico de interesse estratégico, e de se restringir a produção de novos conhecimentos por outras nações, é a exclusividade absoluta deste saber estratégico - o "segredo" tecnológico - pelos povos que detêm a ponta científica.

\section{Referências}

ARON, R. Paz e guerra entre as nações. Brasília: UnB, 2002.

CORNWELL, J. Os cientistas de Hitler: ciência, guerra e o pacto com o demônio. Rio de Janeiro: Imago, 2003.

DAVIDSON, N. The role of scientific discovery in the establishment of the first biological weapons programmes. In: Bradford Science and Technology Report n. 5. October, 2005. Disponível em: www.info.brad.ac.uk. Acesso em nov. 2005.

DIAMOND, J. Armas, germes e aço: os destinos das sociedades humanas. Rio de Janeiro: Record, 2003.

FIORI, J. L. Formação, expansão e limites do poder global. in: FIORI, J. L. (Org.). O poder americano. Petrópolis: Vozes, 2004, p. 11-64.

FRANZ, D. R. et al The U.S. biological warfare and biological defense programs. In: SIDELL, F. R. et al. Medical aspects of chemical and biological warfare. Washington, DC: TMM Publications, 1997, p. 425-436.

FOLHA DE SÃO PAULO. Ciência, São Paulo, 2 jan. 2002.

HOBSBAWM, E. Era dos extremos: o breve século XX [1914-1991]. São Paulo: Schwarcz, 1995.

KENNEDY, P. Ascensão e queda das grandes potências: transformação econômica e conflito militar de 1500 a 2000. Rio de Janeiro: Campus, 1989.

MCNEILL, W. H. The pursuit of power. Chicago: The University of Chicago Press, 1982.

MEDEIROS, C. A. O desenvolvimento tecnológico americano no pós-guerra como um empreendimento militar. In: FIORI, J. L. (Org.). O poder americano. Petrópolis: Vozes, 2004, p. 225-262.

MILLER, J.; ENGELBERG, S.; BROAD, W. Germes: as armas biológicas e a guerra secreta da América. Rio de Janeiro: Ediouro, 2002. 
MONIZ-BANDEIRA, L. A. Formação do Império Americano: da guerra contra a Espanha à guerra no Iraque. Rio de Janeiro: Civilização Brasileira, 2005.

MORGENTHAU, H. J. A política entre as nações: a luta pelo poder e pela paz. Brasília: UnB, 2003.

PARKER, G. The Military Revolution: military innovation and the rise of the West (1500-1800). Cambridge: Press of University of Cambridge, 1996.

RIFKIN, J. O século da biotecnologia: a valorização dos genes e a reconstrução do mundo. São Paulo: Makron Books, 1999.

SFEZ, L. A saúde perfeita: crítica de uma nova utopia. São Paulo: Loyola, 1996.

UNITED STATES NATIONAL ACADEMIES. Globalization, Biosecurity and the Future of the Life Sciences. Washington, D.C.: The National Academies Press, 2001.

WALLERSTEIN, I. The modern world system. New York: Academic Press, 1974. WILKIE, T. Projeto Genoma Humano: um conhecimento perigoso. Rio de Janeiro: Jorge Zahar, 1994.

\section{NOTAS}

- Formação em Biomedicina e especialização em Saúde Coletiva pela UEL; Mestrado e Doutorado em Saúde Coletiva pelo IMS-UERJ; assessora de Cooperação Internacional da ENSP-Fiocruz. Endereço eletrônico: eneida@ensp.fiocruz.br.

${ }^{1}$ Texto elaborado a partir da tese de doutoramento Guerra e desenvolvimento biológico: o caso da biotecnologia e da genômica na segunda metade do século XX, defendida no IMSUERJ, em março de 2006, sob orientação do prof. Dr. José Luís da Costa Fiori, com financiamento da FAPERJ. Este trabalho foi apresentado na forma de pôster no $8^{\circ}$ Congresso Brasileiro de Saúde Coletiva e $11^{\circ}$ Congresso Mundial de Saúde Pública, realizado no Rio de Janeiro, em agosto de 2006. 
${ }^{2}$ Massachusetts Institute of Technology (MIT).

${ }^{3}$ California Institute of Technology (CALTECH).

${ }^{4}$ National Defense Research Council (NDRC).

${ }^{5}$ Office Defense Research Council (ODRC).

${ }^{6}$ Department of Defense (DoD).

${ }^{7}$ Department Advanced Research Projects Agency (DARPA).

${ }^{8}$ Advanced Research Projects Agency (ARPA).

${ }^{9}$ Defense Science Board (DSB).

${ }^{10}$ Stanford Electronic Laboratory (SEL).

${ }^{11}$ O Projeto Genoma Humano foi elaborado em meados da década de 1980, executado ao longo de toda a década de 1990 através de um consórcio técnico internacional de grande envergadura, viveu sua apoteose com o anúncio do primeiro rascunho do genoma humano no ano 2000 e foi finalizado em 2003.

${ }^{12}$ National Institutes of Health (NIH). 
The Biological development in connection with the war

The XX Century was the scenario for the construction of a system devoted to operationalizing the strategic science of the great potentials named the Big Science. This system comprehends a vast institutional and integrated network, the "military-industrial-academic complex", which carries out strategic research and guides high quality science. The objective of this study was to investigate the logics of such construction under the perspective of power, highlighting a counterpoint between the technological development of Physics and Biology. The power movement points to some characteristics, that theoretically reflect the incentive to the induction of the scientific development of modern times, potentialized during the atomic age by the manufacturing of high technology weapons. In this perspective one can search the relevance of the biological development of political-military interest in the three-generation manufacturing of weapons throughout the XX Century, and the participation in the armaments race. This historiographic analysis encompasses the decades of 1940 through 1980, in an attempt to show the ethnical-political convergence in the paths taken by the biological development and the biological war which eventually led to a scientific and military connection at the beginning of the biotechnological era.

Key words: biotechnology; Big Science; power; biological war; history. 


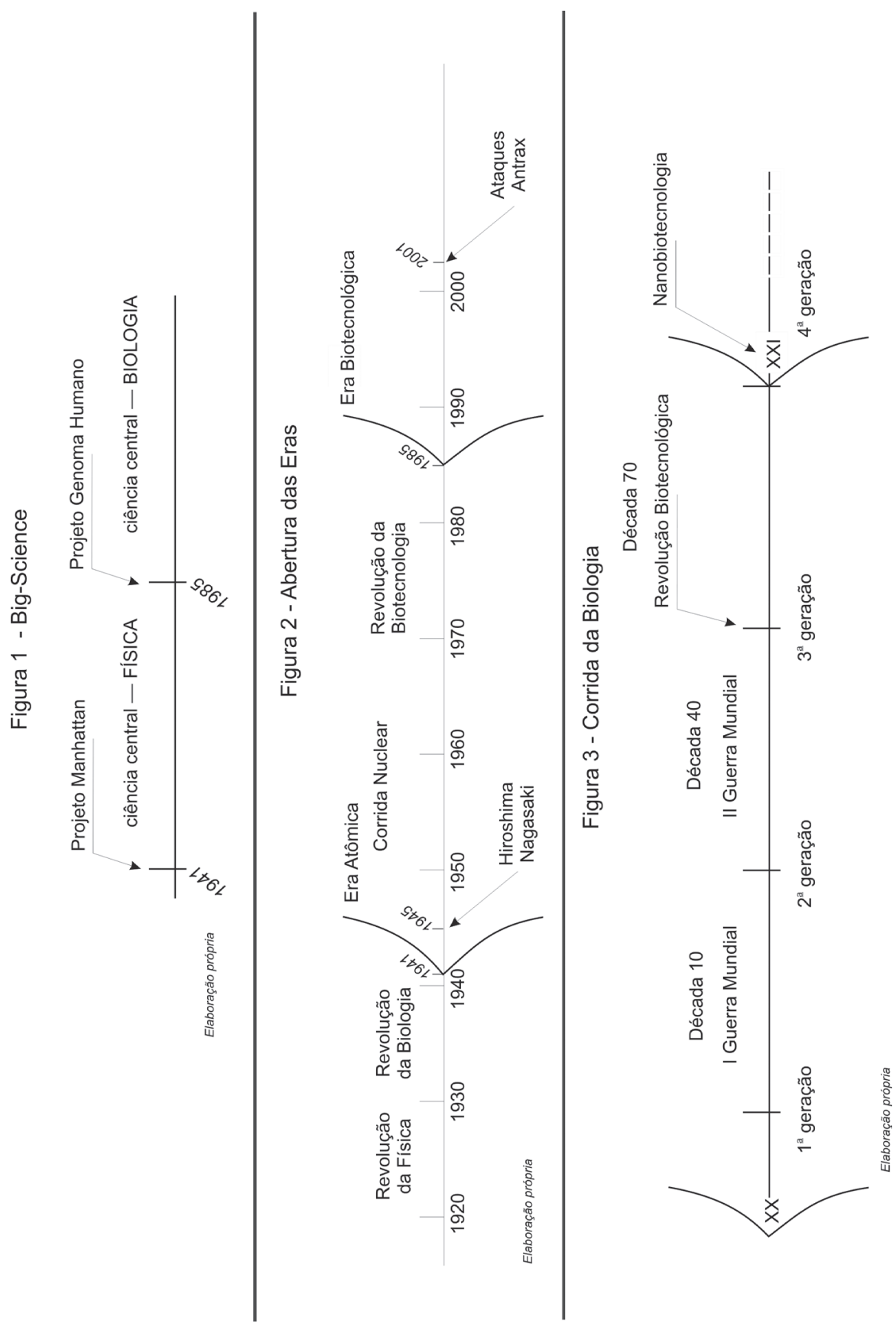

